\title{
Overexpression of Toll-Like Receptor 4 Contributes to Phagocytosis of Salmonella Enterica Serovar Typhimurium via Phosphoinositide 3-Kinase Signaling in Sheep
}

\author{
Sutian Wanga Shoulong Denga,b Yang Cao ${ }^{a} \quad$ Rui Zhang ${ }^{a} \quad$ Zhixian Wang ${ }^{a}$ \\ Xiaojing Jiang ${ }^{a}$ Jiahao Wang ${ }^{a}$ Xiaosheng Zhang ${ }^{c}$ Jinlong Zhang ${ }^{c}$ Guoshi Liu $^{a}$ \\ Zhengxing Lian ${ }^{a}$ \\ aBeijing Key Laboratory for Animal Genetic Improvement, National Engineering Laboratory for Animal \\ Breeding, Key Laboratory of Animal Genetics and Breeding of the Ministry of Agriculture, College of \\ Animal Science and Technology, China Agricultural University, Beijing, 'bState Key Laboratory of Stem \\ Cell and Reproductive Biology, Institute of Zoology, Chinese Academy of Sciences, Beijing, 'Tianjin \\ Institute of Animal Sciences, Tianjin, China
}

\section{Key Words}

Transgenic sheep • Toll-like receptor $4 \cdot$ Phagocytosis $\bullet$ PI3K $\bullet$ Scavenger receptor

\begin{abstract}
Background/Aims: Phagocytosis of bacteria by monocytes/macrophages can trigger the immune response and the clearance of bacteria. This innate immune response involves Toll-like receptor 4 (TLR4). However, much remains unknown about the mechanism of TLR4-regulated phagocytosis of Salmonella enterica serovar Typhimurium (S. typhimurium) within sheep monocytes/macrophages. Here, we aimed to address these knowledge gaps by infecting transgenic sheep overexpressing TLR4 with $S$. typhimurium and examining the phagocytic mechanisms involved. Methods: Transgenic sheep were generated by microinjection of the constructed plasmids into fertilized eggs. Monocytes/macrophages isolated from sheep peripheral blood were stimulated with LPS and S. typhimurium. Phagocytosis-related factor expression, phagocytic ability, and adhesion were then determined. TLR4/phosphatidylinositide 3-kinase (PI3K) signaling was inhibited to investigate if this pathway is involved in changes in bacterial internalization in sheep. Results: We found that TLR4 overexpression effectively activated the PI3K signaling pathway and upregulated the expression of scavenger receptors. Additionally, actin polymerization and adhesive capacity were both enhanced in TLR4overexpressing sheep monocytes/macrophages. TLR4 inhibition decreased S. typhimurium
\end{abstract}

\footnotetext{
Zhengxing Lian Beijing Key Laboratory for Animal Genetic Improvement, National Engineering Laboratory for Animal Breeding, Key Laboratory of Animal Genetics and Breeding of the Ministry of Agriculture, Beijing (China) E-Mail lianzhx@cau.edu.cn
}

\section{KARGER}




\section{Cellular Physiology Cell Physiol Biochem 2018;49:662-677 \\ \begin{tabular}{l|l|l} 
DOI: 10.1159/000493032 & $\begin{array}{l}\text { O 2018 The Author(s). Published by S. Karger AG, Basel } \\
\text { www.karger.com/cpb }\end{array}$
\end{tabular} \\ Wang et al.: Overexpression of TLR4 Increase Phagocytosis in Transgenic Sheep}

phagocytosis by reducing the actin polymerization and adhesive capacity of cells. Furthermore, inhibition of PI3K markedly impaired TLR4-dependent phagocytosis by restraining actin polymerization and scavenger receptor expression and reduced the adhesive capacity of the monocytes/macrophages. Conclusion: Our findings indicate that overexpression of TLR4 enhances phagocytosis through PI3K signaling and the subsequent activation of actin polymerization and scavenger receptors in sheep monocytes/macrophages infected with $S$. typhimurium.

\section{Introduction}

Salmonella is an intracellular Gram-negative bacterium found worldwide that causes gastrointestinal infections in livestock. Salmonella has been widely identified in sheep in many countries [1-3] and can cause acute gastroenteritis, sepsis, and even abortion, which gravely affect animal health and production [4]. Depending on the type III secretion system present in bacteria, these bacteria can invade and survive within phagocytes. The Salmonella pathogenicity island also plays an important role in these processes [5, 6]. During infection, the host innate immune system is the first line of defense against pathogens. As pattern recognition receptors, Toll-like receptors (TLRs) are pivotal to the recognition of all kinds of pathogens, including Salmonella [7, 8]. Salmonella expresses multiple ligands for TLRs, such as LTA, LPS, and CpG-DNA, and these ligands trigger the activation of various signaling pathways, which can result in filamentous actin (F-actin) re-arrangement and phagocytosis $[9,10]$.

TLR4 is mainly expressed in monocytes/macrophages and epithelial cells in sheep; it is also abundant in peripheral blood monocytes [11]. Lipopolysaccharide (LPS) is the most common ligand of TLR4 and is also the major component of the cell wall of Gram-negative bacteria such as Salmonella. LPS recognition activates TLR4 signaling pathways, which leads to the activation of multiple signaling pathways, such as nuclear factor kappa B (NF- $\kappa B$ ), mitogen-activated protein kinase (MAPK), and Janus kinase-phosphoinositide 3-kinase (JAK-PI3K). Importantly, the JAK-PI3K signaling pathway is involved in the internalization of bacteria [12, 13]. Of the four isoforms of PI3K $(\alpha, \beta, \gamma$, and $\delta)$, PI3K $\gamma$ participates in neutrophil migration [14]. The PI3K signaling pathway is involved in the regulation of pseudopod stretching [15] and is necessary for Fc gamma receptor-mediated phagocytosis [16]. Inhibition of PI3K blocks phagocytosis through modification of actin polymerization at sites of uptake [17].

Notably, actin cytoskeleton re-arrangement is always involved regardless of how bacterial internalization occurs [18]. Additionally, the adhesive capacity of phagocytes promotes phagocytosis $[19,20]$. Scavenger receptors are also involved in the immune response. They have diverse ligands, including low-density lipoprotein (LDL), phosphatidylserine, and LPS [21-23]. Many of these receptors are expressed in macrophages. They not only participate in phagocytosis of apoptotic cells, but also influence the adhesive capacity of phagocytes $[24,25]$. Class A scavenger receptors mediate multiple functions, including adhesion. Macrophage activation can increase SR-A expression and SR-A-dependent adhesion [26]. CD36 is a member of the class B scavenger receptors and is expressed in immunocytes. Several studies have indicated that CD36 functions as a signaling molecule that can transmit signals via MAPK [27]. Furthermore, CD36 has been implicated in actin cytoskeleton rearrangement [28]. Inhibition of PI3K can decrease the expression of scavenger receptors [29] and influence scavenger receptor-mediated cell adhesion [30]. These results suggest the possible interactions among TLR4, scavenger receptors, and PI3K during bacterial internalization.

TLR4-overexpressing transgenic mice appear to be more sensitive to LPS and Salmonella and exhibit a survival advantage during bacterial infection [31]. Our previous studies showed that overexpression of TLR4 is physiologically important and could trigger a more intense 


\section{Cellular Physiology Cell Physiol Biochem 2018;49:662-677 \begin{tabular}{l|l} 
DOI: 10.1159/000493032 & $\begin{array}{l}\text { O 2018 The Author(s). Published by S. Karger AG, Basel } \\
\text { www.karger.com/cpb }\end{array}$
\end{tabular} \\ Wang et al.: Overexpression of TLR4 Increase Phagocytosis in Transgenic Sheep}

immune response, such as secretion of various interleukins, rapid neutrophil infiltration, and increased oxidative stress [32-34]. In the present study, we continued to survey whether TLR4-overexpressing sheep have improved bacterial phagocytosis.

\section{Materials and Methods}

\section{Ethical statement}

All transgenic sheep production and sample collection procedures were performed in accordance with a protocol from the Animal Welfare Committee of the China Agricultural University (Permit Number: XK662).

\section{Production and identification of transgenic sheep}

Transgenic sheep were produced by microinjecting the plasmid vector into fertilized sheep eggs (Fig 1A). The presence of the exogenous TLR4 genes was confirmed by Southern blotting; the genomic DNA used in this experiment was extracted from ear tissue. The probe used in Southern blotting was labelled with digoxigenin (Roche Diagnostics, Mannheim, Germany) and prepared by PCR using the following primers: forward, $5^{\prime}$-ACTGG TAAAGAACTTGGAGGAGG-3'; reverse, 5'-CCTTCACAGCATTCAACAGACC- ${ }^{\prime}$. The size of the Southern hybridization probe was $671 \mathrm{bp}$. Genomic DNA (20 ng) was digested with Hind III (NEB, Beverly, MA, USA). The expression level of TLR4 was quantified by qRT-PCR. In brief, mononuclear cells from 6 Southern blot-positive transgenic sheep and 6 wild-type sheep were isolated from venous blood with lymphocyte separation medium (Sigma-Aldrich, St. Louis, MO, USA). RNA was extracted from mononuclear cells with the RNeasy Plus Mini kit (Qiagen) and reverse-transcribed into cDNA using the PrimeScript RT reagent kit (TaKaRa Bio, Japan). The primers used for qRT-PCR of TLR4 were as follows: forward, 5' -ATCATCAGCGTGTCGGTTGTCA-3'; reverse, 5' -GCAGCCAGCAAGAAGCATCAG-3'. GAPDH was used as an internal standard; the primers used were as follows: forward, $5^{\prime}$-GCAAGTTCCACGGCACAG- $3^{\prime}$; reverse, 5'-GGTTCACGCCCATCACAA-3'. Real-time PCR reactions were performed using a MX3000P instrument (Agilent Technologies, Santa Clara, CA, USA).

\section{Sheep monocyte-macrophages isolation and culture}

Six transgenic sheep and six wild-type sheep were divided into two groups. In brief, $50 \mathrm{~mL}$ of blood was collected from the jugular vein of adult sheep belonging to the Tianjin Institute of Animal Sciences. Peripheral blood mononuclear cells (PBMCs) were obtained from the peripheral blood using lymphocyte separation medium. Cells $\left(1 \times 10^{5}\right)$ were seeded into each well of 48-well plates; for each sample, at least three replicates were included. After incubation for $2 \mathrm{~h}$ at $37^{\circ} \mathrm{C}$ in a $5 \% \mathrm{CO}^{2}$ incubator, the non-adherent cells were removed by washing three times with phosphate-buffered saline (PBS). The adherent cells were then cultivated in RPMI1640 (Gibco, Grand Island, NY, USA) medium containing 10\% FBS (Gibco), and the cells were incubated at $37^{\circ} \mathrm{C}$ in a $5 \% \mathrm{CO}^{2}$ incubator for $48 \mathrm{~h}$, changing the medium every $24 \mathrm{~h}$. After $48 \mathrm{~h}$ of incubation and washing off non-adherent cells, the adherent cells were mainly composed of monocytemacrophages [11].

\section{Analysis of internalization-associated genes by real-time PCR}

Monocyte-macrophages were incubated with LPS or $S$. typhimurium. After stimulation, monocytemacrophages were collected for RNA extraction with the RNeasy Plus Mini kit and then reverse-transcribed into cDNA using the PrimeScript RT reagent kit. The expression of TLR4, MyD88, Jak2, NF-кB, PI3K, P38, CD14, and scavenger receptor mRNA was measured by real-time PCR. The primers used in this experiment are shown in Table 2. Real-time PCR reactions were performed using a MX3000P PCR machine (Agilent Technologies, Santa Clara, CA, USA). The SYBR Premix Ex Taq II kit (TAKARA) was used for qRT-PCR. The reaction mixture contained $10.0 \mu \mathrm{L}$ of SYBR Premix Ex Taq II, $0.8 \mu \mathrm{L}$ of forward primer, $0.8 \mu \mathrm{L}$ of reverse primer, $0.4 \mu \mathrm{L}$ of ROX reference dye II, $2 \mu \mathrm{L}$ of cDNA template, and $6 \mu \mathrm{L}$ of $\mathrm{dH}_{2} \mathrm{O}$. The three-step protocol reaction conditions were as follows: initial incubation at $95^{\circ} \mathrm{C}$ for $30 \mathrm{~s}$ followed by 40 cycles of $95^{\circ} \mathrm{C}$ for $5 \mathrm{~s}$ and $58^{\circ} \mathrm{C}$ or $62^{\circ} \mathrm{C}$ for $30 \mathrm{~s}$, and an extension step at $72^{\circ} \mathrm{C}$ for $30 \mathrm{~s}$. GAPDH was used to normalize the relative expression of each gene. 


\section{Cellular Physiology Cell Physiol Biochem 2018;49:662-677 \begin{tabular}{l|l|l} 
and Biochemistry Published online: 30 August, 2018 & $\begin{array}{l}\text { @ } 2018 \text { The Author(s). Published by S. Karger AG, Basel } \\
\text { www.karger.com/cpb }\end{array}$ \\
\hline
\end{tabular}

\section{Western blot analysis}

In brief, after the cells were harvested, they were lysed by RIPA buffer containing protease inhibitors and phosphatase inhibitors. Protein concentrations were quantified with BCA Protein Assay Kit (Thermo Scientific, USA). Cell lysates were resolved on 10\% SDS-PAGE and then transferred to a PVDF (Millipore, USA). The blots were incubated with phospho-Akt rabbit mAb (Cell Signaling Technology), and GAPDH (Proteintech, USA). The secondary antibodies were $800 \mathrm{CW}$ goat anti-rabbit IgG (LI-COR, USA). After incubation with secondary antibodies, the membranes were visualized using ECL chemiluminescence (Thermo Scientific, USA).

\section{Phagocytosis assay}

To detect bacterial phagocytosis, monocyte-macrophages were infected with S. typhimurium. Before infection, monocyte-macrophages were washed three times in PBS without antibiotics and then mixed with S. typhimurium at an MOI of 10 or 100 , centrifuged at $100 \times \mathrm{g}$ for $10 \mathrm{~min}$, and incubated at $37^{\circ} \mathrm{C}$ in a $5 \% \mathrm{CO}^{2}$ incubator for 5, 15, or 30 min. Cells were then washed twice with PBS and incubated in RPMI1640 medium containing $10 \% \mathrm{FBS}$ and gentamicin $(30 \mu \mathrm{g} / \mathrm{mL})$ for $30 \mathrm{~min}$ to kill any non-internalized bacteria. To monitor the phagocytized bacteria at different time points, cells were washed three times with PBS and then lysed with $1 \%$ Triton X-100. After serial dilution, the last dilution was spread onto agar plates. After overnight culture of the bacteria, the number of viable CFUs was recorded to estimate the number of internalized bacteria.

To determine whether TLR4-PI3K signaling participates in bacterial internalization, we used the TLR4 and PI3K inhibitors CLI095 and LY294002 (Sigma-Aldrich) prior to infection with S. typhimurium to inhibit their respective signaling. Bacterial internalization-associated genes involved in these signaling pathways were evaluated by qRT-PCR as described above. Primer sequences are shown in Table 2.

\section{Quantitative measurement of F-actin}

After stimulation of monocyte-macrophages with $S$. typhimurium as indicated above, cells were washed twice with warm PBS $\left(37^{\circ} \mathrm{C}\right)$ for $10 \mathrm{~min}$. Cells were fixed with $4 \%$ paraformaldehyde for $20 \mathrm{~min}$ at $22^{\circ} \mathrm{C}$, permeabilized with $0.1 \%$ Triton X-100 for $5 \mathrm{~min}$ at $22^{\circ} \mathrm{C}$, and then washed twice more with warm PBS $\left(37^{\circ} \mathrm{C}\right)$ for $10 \mathrm{~min}$. After a $20 \mathrm{~min}$ incubation with immunol staining blocking buffer (Beyotime, Shanghai, China), cells were continuously incubated with fluorescein isothiocyanate (FITC) labelled phalloidin (SigmaAldrich) for $1 \mathrm{~h}$ at $37^{\circ} \mathrm{C}$ in an incubator. Cells were washed three times with PBS, and F-actin content was quantified with ImageXpress (Molecular Devices).

To determine whether TLR4 participates in driving the reorganization of F-actin, we used the TLR4 and PI3K inhibitors CLI-095 and LY294002 (Sigma-Aldrich), respectively, prior to infection with S. typhimurium to inhibit signaling. Determination of F-actin content was performed as described above.

\section{Bacterial staining and adhesion assay}

S. typhimurium was labelled with rhodamine B (red) as follows. S. typhimurium $(1 \times 109 / \mathrm{mL}$ in PBS) was incubated with rhodamine B $(10 \mathrm{mg} / \mathrm{mL})$ for $2 \mathrm{~h}$ at $37^{\circ} \mathrm{C}$ and then washed three times with PBS. The adhesive capacity of the monocyte-macrophages was assessed by incubation with rhodamine B-labelled bacteria $(10: 1)$ for $15 \mathrm{~min}$ at $37^{\circ} \mathrm{C}$ and then washing three times to remove non-adhesive bacteria. Cells were then fixed using paraformaldehyde (4\%) and then subjected to ImageXpress Micro analysis.

\section{Image Acquisition on the ImageXpress}

ImageXpress micro (Molecular Devices) was used for automated imaging. In the MetaXpress software, under Acquisition Loops, laser-based focusing was enabled. Under Wavelengths, FITC, DAPI and Texas red were selected with an exposure of $500 \mathrm{~ms}$. The autofocus was set to Laser with Z-offset. The application settings for identification of mean fluorescence intensity of each cell were as follows: approximate min width, $8 \mu \mathrm{m}$; approximate max width, $20 \mu \mathrm{m}$; intensity above local background, 20 gray levels.

\section{Statistical analyses}

All experiments were repeated three times and the number of sheep in each group was no less than three. All data are reported as the mean \pm SEM, and all statistical analyses were performed using the Student's t-test. $\mathrm{P}<0.05$ was considered to be significant. 


\section{Cellular Physiology and Biochemistry Published online: 30 August, 2018 \begin{tabular}{l|l} 
DOI: 10.1159/000493032 2018 The Author(s). Published by S. Karger AG, Basel \\
www.karger.com/cpb
\end{tabular}

\section{Results}

Overexpression of TLR4 in transgenic sheep

Transgenic sheep were generated via microinjection of a linear fragment containing the Ovis aries TLR4 gene (Fig. 1A); Southern blotting was subsequently performed to detect positive individuals. After digestion of the sheep genome using HindIII, the 5-kb band represented endogenous TLR4 on chromosome 2 and the 3-kb band represented the exogenous TLR4 fragment, which was only present in positive transgenic individuals (Fig. 1B). As shown in Table 1, the Southern blotting positive rate for F1 generation was $46.73 \%$. The expression of TLR4 was higher in transgenic sheep monocytes/macrophages derived from peripheral blood than in wild-type sheep ( $\mathrm{P}<0.05$; Fig. 1C-E). These findings demonstrated that we successfully generated TLR4-overexpressing sheep.

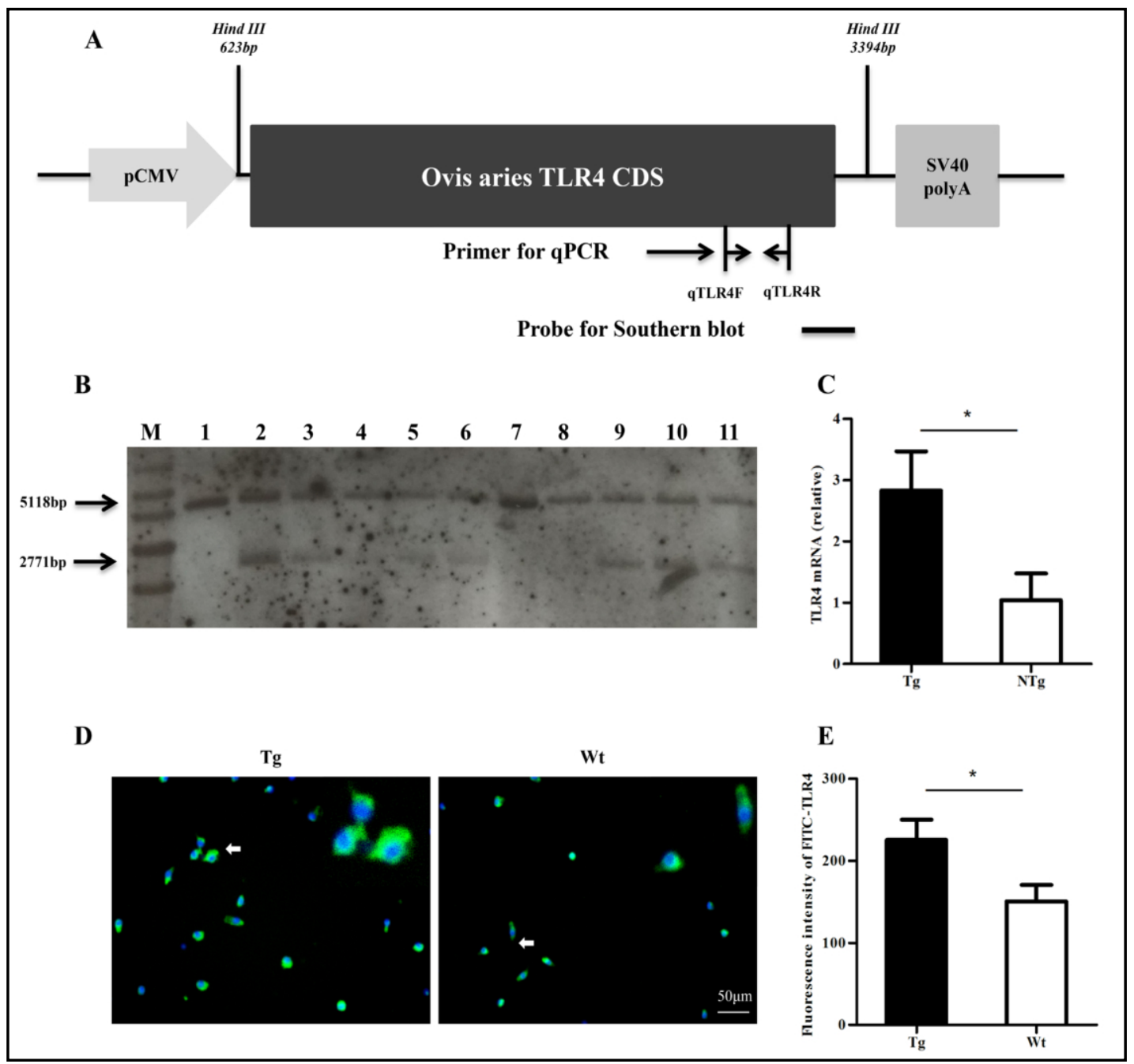

Fig. 1. Overexpression of TLR4 in sheep. (A) Structure of CMV-TLR4 vector. (B) Transgenic TLR4overexpressing sheep were evaluated by Southern blot analysis. The exogenous TLR4 fragment is the 2771 bp band, and the $5118 \mathrm{bp}$ band is the endogenous TLR4 fragment. M: marker (1 kb ladder), the transgenic sheep were: $2,3,5,6,9,10,11$ and the wild-type sheep were: $1,4,7,8$. (C-E) TLR4 expression in monocytemacrophages was measured by quantitative real-time PCR (qRT-PCR) and immunofluorescence. TLR4 was labelled by FITC, nuclei were stained by Hoechst 33342 (20× ELWD ADM). Tg: transgenic sheep; Wt: wildtype sheep. All data are presented as the mean \pm SEM from three experiments, ${ }^{*} \mathrm{P}<0.05$. 


\section{Cellular Physiology Cell Physiol Biochem 2018;49:662-677

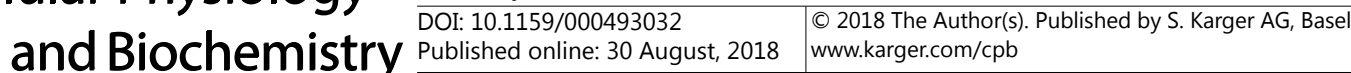 \\ Wang et al.: Overexpression of TLR4 Increase Phagocytosis in Transgenic Sheep}

TLR4 overexpression activates multiple pathways in LPSstimulated sheep monocytes/ macrophages

First, we examined the signaling pathways activated by LPS after stimulation of monocytes/ macrophages with LPS (100 ng/ $\mathrm{mL}$ ). As shown in Fig. 2A, stimulation with LPS enhanced the expression of TLR4, Myd88, and scavenger receptor. Then, we examined the signaling activated by LPS in transgenic sheep. We stimulated monocytes/macrophages with LPS for 5, 30, and $60 \mathrm{~min}$. Compared with the wild-type group, the transgenic group showed significantly higher expression of TLR4 and Myd88 after LPS stimulation at all time points ( $\mathrm{P}<0.05$; Fig. $2 \mathrm{~A}$ and $\mathrm{B}$ ). Myd88 plays an important role in cell signaling transduction and our findings indicate that TLR4 could regulate Myd88 expression. Moreover, after stimulation with LPS for $5 \mathrm{~min}$, the transcription levels of TLR4, Myd88, NF$\kappa B, S R-A$, and $C D 36$ were significantly higher in the transgenic group than in the wild-type group ( $\mathrm{P}<0.05$; Fig. $2 \mathrm{~B}-\mathrm{F}$ ). These results showed that TLR4 triggered activation of the $N F-$ $\kappa B$ and scavenger receptors. In addition, $T L R 4, M y d 88, N F-\kappa B, S R-A$, and $C D 36$ expression in the transgenic group peaked at $30 \mathrm{~min}$. We assessed the activation of the PI3K signaling pathway by determining the phosphorylation of Akt, a downstream target of PI3K, using anti-phospho-Akt antibody. LPS stimulation induced upregulated phosphorylation of Akt in the transgenic group compared with the wild-type group (Fig. 2G).

\section{TLR4 overexpression leads to increased phagocytosis of S. typhimurium}

Phagocytosis of bacteria is an important function of monocytes/macrophages. LPS is the main component of $S$. typhimurium, and it can be recognized by TLR4 and trigger immune responses. To investigate whether TLR4 overexpression could influence the internalization of $S$. typhimurium, monocytes/macrophages were incubated with $S$. typhimurium at a multiplicity of infection (MOI) of 10 or 100, respectively. At either MOI, S. typhimurium increased the expression of TLR4 (Fig. 3A). We next found that the levels of intracellular bacteria were higher in the transgenic group than in the wild-type group at both doses within $30 \mathrm{~min}(\mathrm{P}<0.05$; Fig. 3B-C). Moreover, from an early time point (5 min), the transgenic group showed more powerful phagocytosis of bacteria with an MOI of $10(\mathrm{P}<0.01)$.

To determine which TLR4 downstream factors were involved in this process, we examined multiple factors, including $M y d 88, N F-\kappa B$, scavenger receptor, CD14, and PI3K. As expected, TLR4 mRNA levels were significantly higher in the transgenic group at both doses $(\mathrm{P}<0.05$; Fig. 3D and E). The levels of $M y d 88, N F-\kappa B$, scavenger receptor, and p-Akt were higher in the transgenic group than in the wild-type group $(\mathrm{P}<0.05)$. The phagocytosis-related receptors $S R-A$ and $C D 36$ were significantly upregulated in the transgenic group with an MOI of 10 (P $<0.01$; Fig. 3D). Furthermore, to determine whether incubation with $S$. typhimurium altered the polymerization of actin, we measured the F-actin content. TLR4 overexpression enhanced the mean fluorescence intensity of F-actin in each cell population at $30 \mathrm{~min}$ postinfection (P $<0.05$; Fig. $4 \mathrm{~A}$ and B). This finding indicates that TLR4 regulates the accumulation of F-actin. Adhesive capacity was also examined in our experiments, with the results indicating that $T L R 4$ overexpression upregulated adhesive capacity in sheep monocytes/macrophages (Fig. $4 C$ and D). Our adhesion assays suggested that TLR4-overepression not only promoted an increase in the amount of bacteria adhered by individual monocytes/macrophages, but also increased the number of monocytes/macrophages able to participate in bacterial adhesion. 


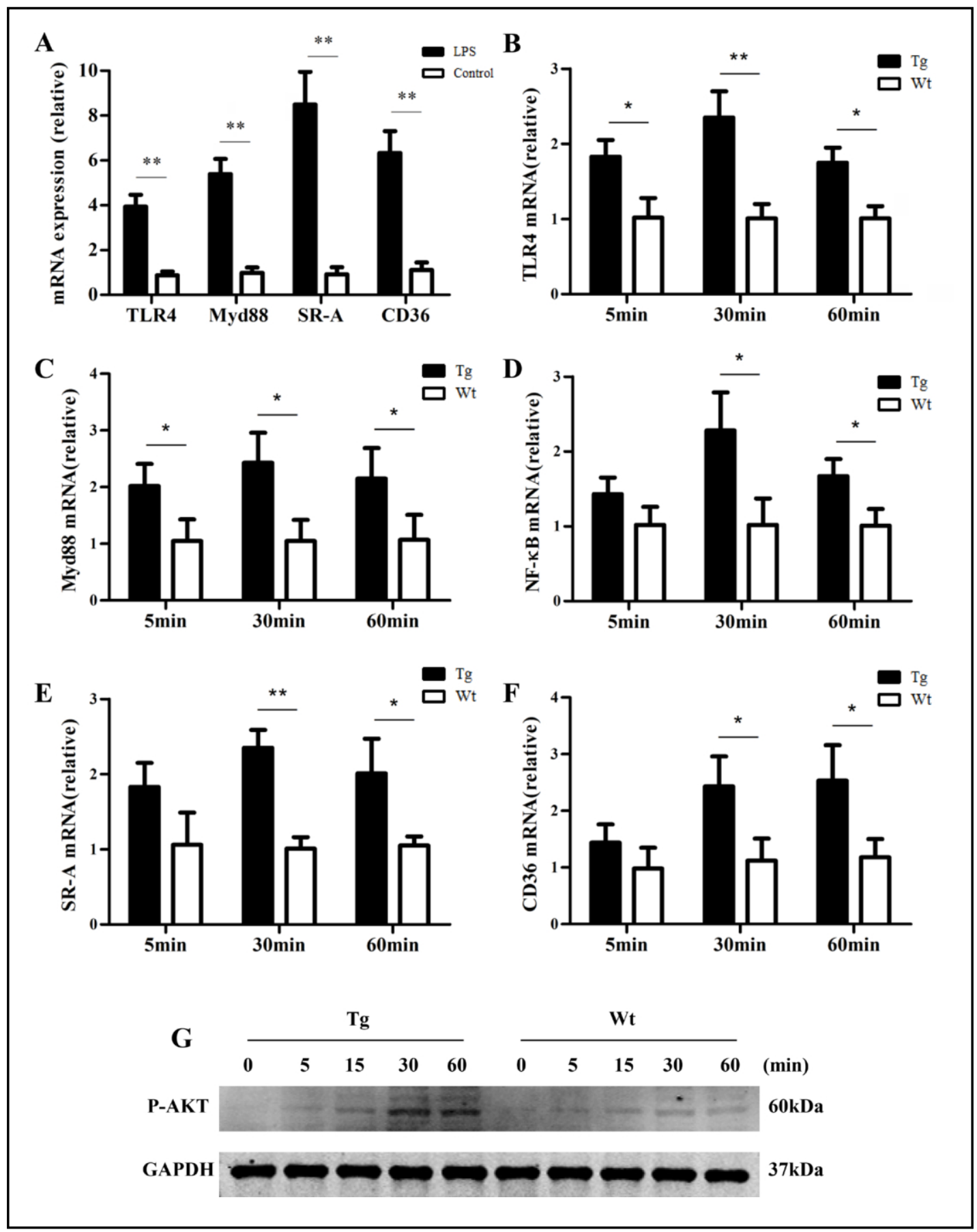

Fig. 2. Activation of scavenger receptor and PI3K signaling pathways by LPS in sheep monocytemacrophages. A shows the mRNA expression of TLR4, Myd88, SR-A, and CD36 increased significantly in LPS stimulation group, B to F show the expression of TLR4, Myd88, NF- $\kappa B$, SR-A, and CD36 at 5 min, 30 min and $60 \mathrm{~min}$ after LPS $(100 \mathrm{ng} / \mathrm{mL})$ stimulation, respectively. G shows the phosphorylation of Akt after LPS stimulation in monocyte-macrophages. Tg: transgenic sheep; Wt: wild-type sheep. All data are presented as the mean \pm SEM from three experiments, ${ }^{*} \mathrm{P}<0.05$. 


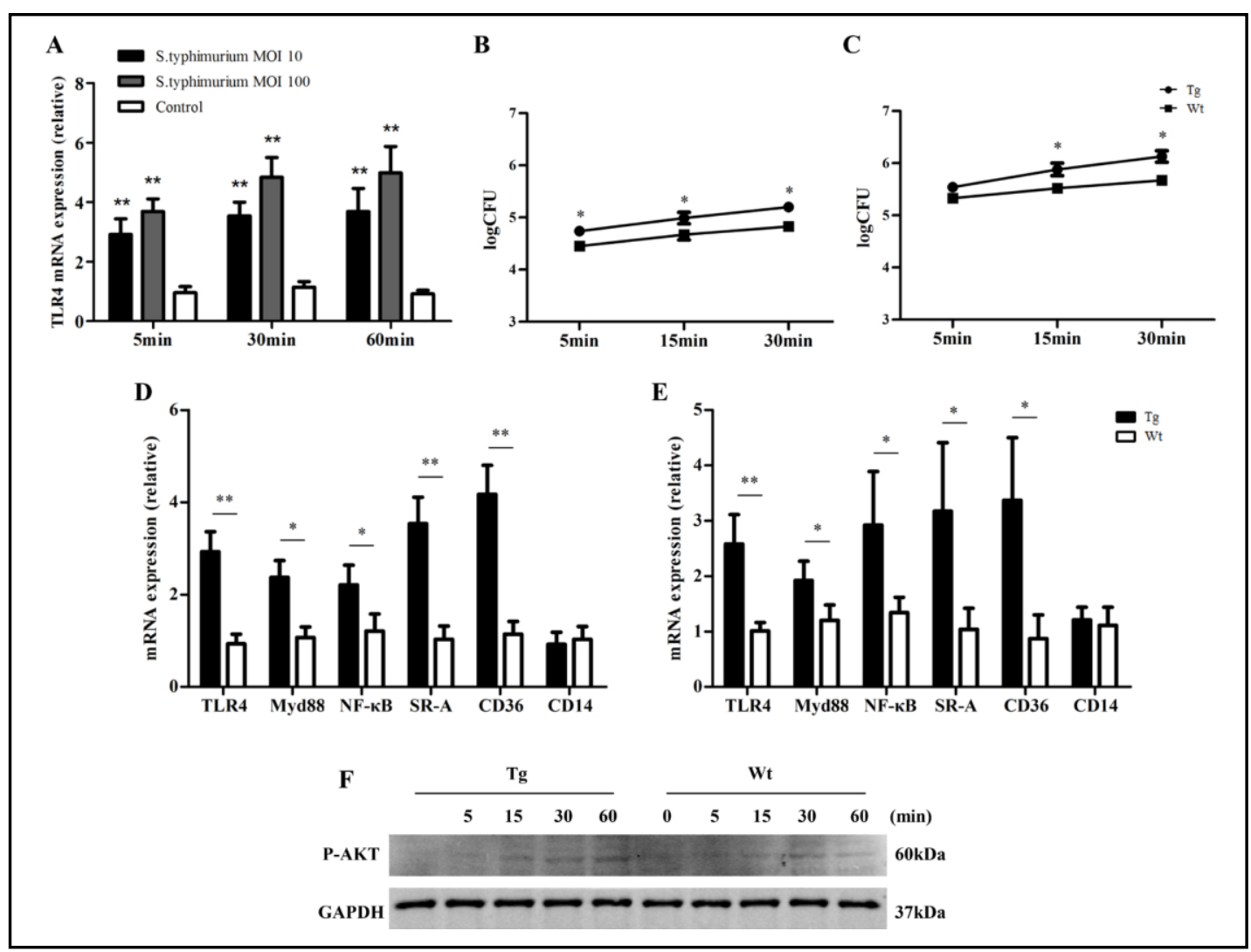

Fig. 3. TLR4-mediated signaling promotes phagocytosis of $S$. typhimurium into sheep monocytemacrophages. (A) Expression of TLR4 after incubation with S. typhimurium (MOI=10, 100) for 5, 30, 60min. (B-C) Bacterial internalization was detected in monocyte-macrophages after incubation with S. typhimurium (A MOI = 10 and B MOI = 100, respectively). (D-E) Expression of TLR4, Myd88, NF- $\kappa B$, SR-A, CD-36, and CD14 after incubation with $S$. typhimurium (30 min, C MOI = 10 and D MOI = 100, respectively). (F) Show the phosphorylation of Akt after $S$. typhimurium stimulation in monocyte-macrophages $(\mathrm{MOI}=10)$. Tg: transgenic sheep; Wt: wild-type sheep. All data are presented as the mean \pm SEM from three experiments, with ${ }^{*} \mathrm{P}<0.05$ and ${ }^{* *} \mathrm{P}<0.01$.

Inhibition of the TLR4 signaling pathway diminishes the phagocytosis of S. typhimurium

To further investigate whether TLR4 is involved in changes in bacterial internalization in sheep, we used the TLR4-specific inhibitor CLI-095. As shown in Fig. 5A, CLI-095 reduced the number of internalized bacteria $(\mathrm{P}<0.05)$; the optimum supplemental level of CLI-095 was $3 \mu \mathrm{M}$. CLI-095 was able to influence multiple factors, include scavenger receptors (Fig. 5B). Myd88, SR-A, and CD36 mRNA levels in the transgenic group were higher at $30 \mathrm{~min}$ postinfection with CLI-095 pretreatment $(3 \mu \mathrm{M})(\mathrm{P}<0.01$; Fig. 5C). The level of phospho-Akt was also decreased by CLI-095 (Fig. 5D). S. typhimurium-induced actin polymerization was lower in the CLI-095-pretreated group than in the DMSO-pretreated group (P $<0.05$; Fig. 5E and F). Furthermore, compared with DMSO pretreatment, CLI-095 pretreatment reduced the adhesive capacity of the sheep monocytes/macrophages (Fig. $5 \mathrm{G}$ and $\mathrm{H}$ ). The adhesion assays indicated that inhibition of the TLR4 signaling pathway not only decreased the amount of bacteria adhered by individual monocytes/macrophages, but also reduced the number of monocytes/macrophages able to participate in bacterial adhesion. In addition, after pretreatment with CLI-095, S. typhimurium-induced actin polymerization and the adhesive capacity of monocytes/macrophages were found to be higher in the transgenic group (Fig. $5 \mathrm{E}$ and $\mathrm{H}$ ). Our data indicate that TLR4 regulates the phagocytosis of S. typhimurium in sheep monocytes/macrophages.

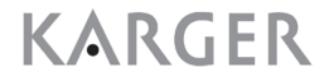




\section{Cellular Physiology and Biochemistry Published online: 30 August, 2018 \begin{tabular}{l|l} 
D 2 2018 The Author(s). Published by S. Karger AG, Basel \\
www.karger.com/cpb
\end{tabular} \\ Wang et al.: Overexpression of TLR4 Increase Phagocytosis in Transgenic Sheep}

Fig. 4. Overexpression of TLR4 promotes phagocytosis of $S$. typhimurium into sheep monocyte-macrophages. (A-B) Fluorescence intensity of F-actin of sheep monocytemacrophages; F-actin was labelled by FITCphalloidin (20× ELWD ADM). (C-D) Adhesive capacity of monocytemacrophages (20× ELWD ADM), S. typhimurium was labelled by rhodamine. Tg: transgenic sheep; Wt: wild-type sheep. All data are presented as the mean \pm SEM from three experiments, with $* \mathrm{P}<0.05$.

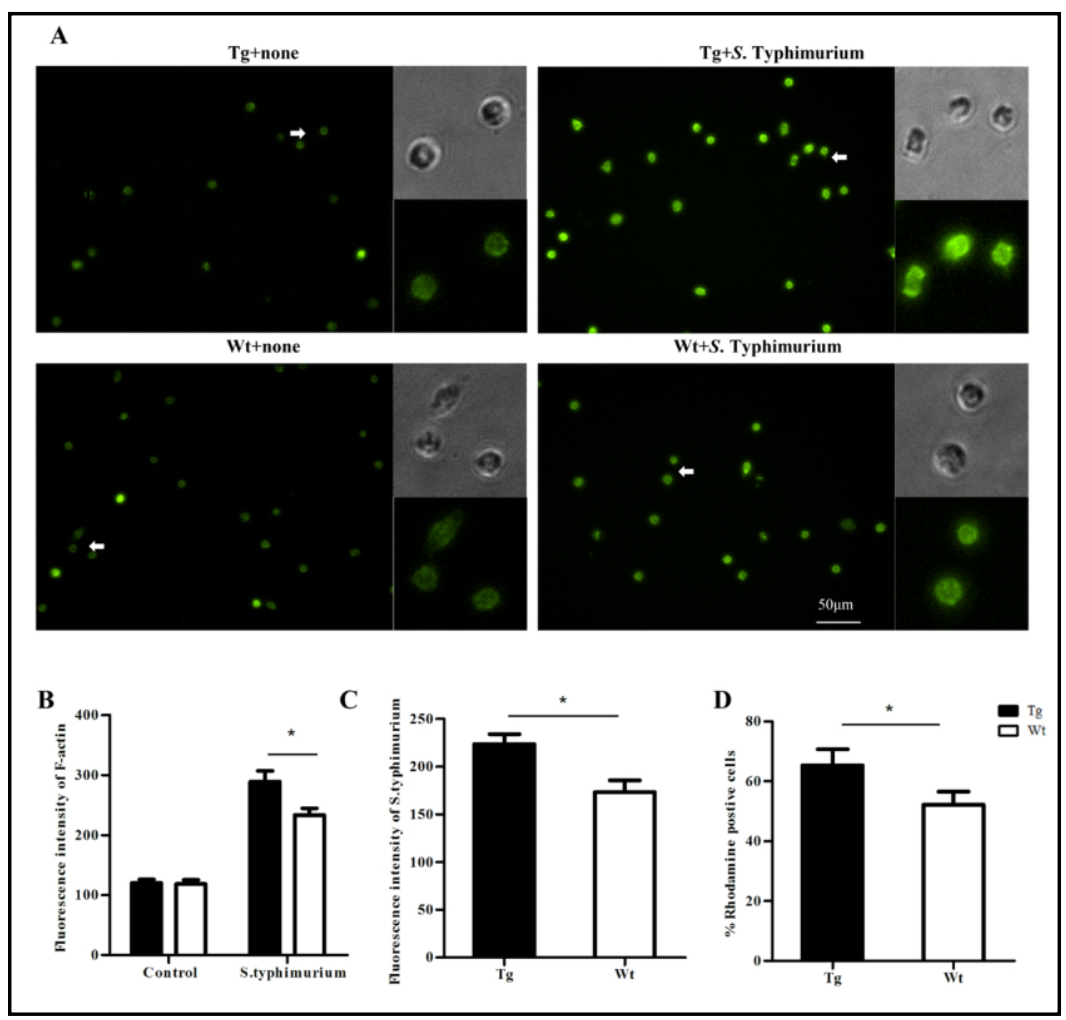

Specific inhibition of the PI3K pathway reduces S. typhimurium phagocytosis

The levels of scavenger receptors and PI3K were consistent with our bacterial internalization results. This suggested that they might be involved in the internalization of S. typhimurium. To examine whether PI3K is involved in phagocytosis in sheep, cells were pretreated with LY294002 to specifically inhibit the PI3K signaling pathway. We found that inhibition of PI3K reduced the internalization of S. typhimurium into monocytes/macrophages (Fig. 6A). Moreover, transcription of scavenger receptors was lower in the LY294002pretreated group than in the control group (Fig. 6B). The mRNA levels of scavenger receptors were higher in the transgenic group (Fig. 6C). Furthermore, the level of phospho-Akt was also decreased by inhibition of PI3K signaling (Fig. 6D). After pretreatment with LY294002, F-actin content was lower in the pretreated group than in the DMSO group. Moreover, F-actin content was higher in the transgenic group after pretreatment with LY294002 (Fig. 6E and F). As expected, the adhesive capacity of sheep monocytes/macrophages was consistent with the expression of scavenger receptors. This meant that inhibition of PI3K reduced the adhesive capacity of sheep monocytes/macrophages (Fig. 6G and H). The TLR4-overexpressing sheep also exhibited higher adhesive capacity than the wild-type group. These data indicated that the PI3K signaling pathway plays an important role in the TLR4-dependent phagocytosis of sheep monocytes/macrophages. 


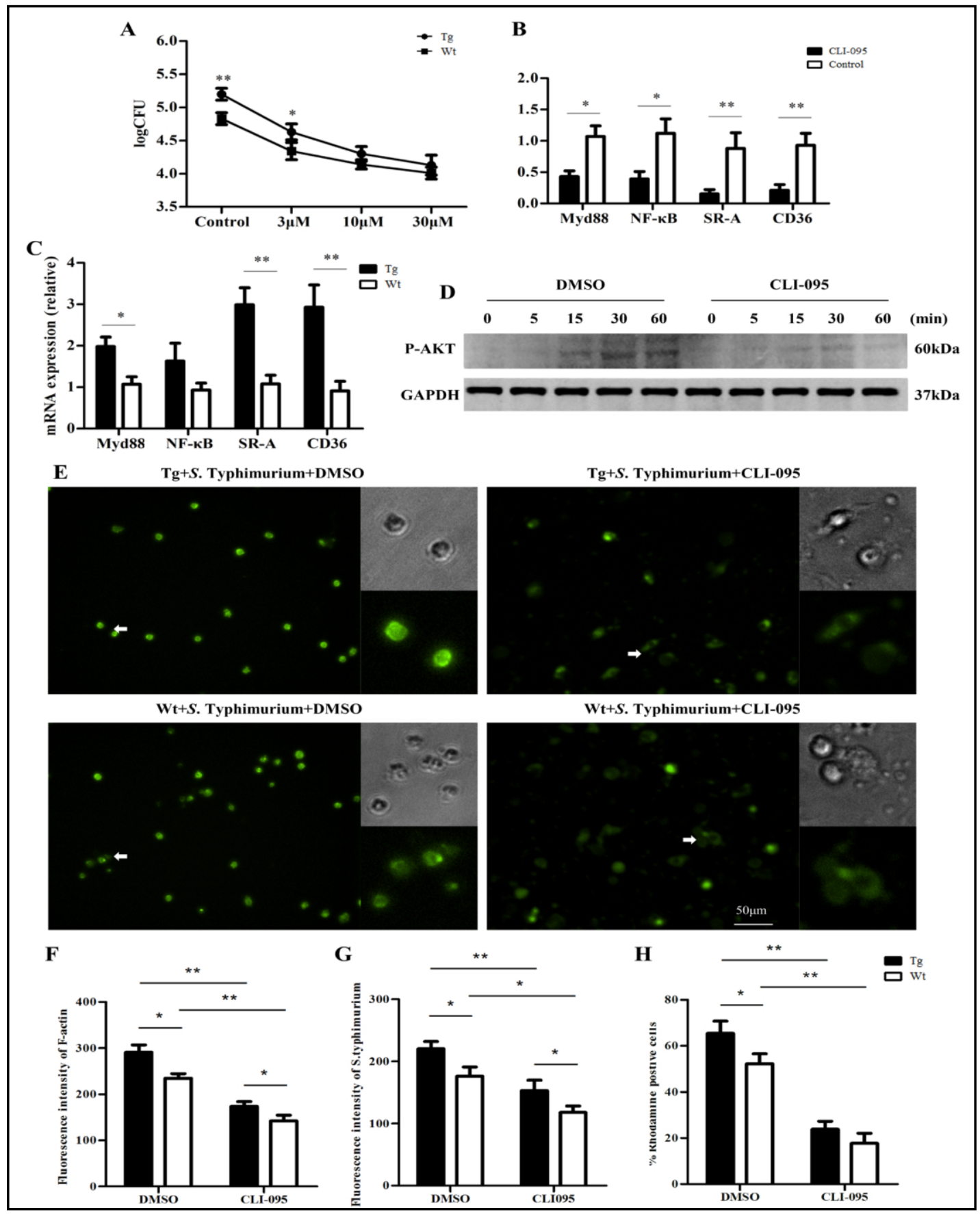

Fig. 5. Inhibition of TLR4 with CLI-095 decreased the phagocytosis of $S$. typhimurium in sheep monocytemacrophages. (A) Monocyte-macrophages were pretreated with DMSO (0.1\%) or CLI-095 (0 to $30 \mu \mathrm{M})$ for $6 \mathrm{~h}$, and then bacterial internalization was detected after incubation with $S$. typhimurium for $30 \mathrm{~min}$ $(\mathrm{MOI}=10)$. (B-C) qRT-PCR analysis of expression of Myd88, NF- $\mathrm{BB}$, SR-A and CD36 from sheep monocytemacrophages pretreated with CLI-095 $(3 \mu \mathrm{M})$ and infected with $S$. typhimurium $(30 \mathrm{~min}, \mathrm{MOI}=10)$. (D) Show the phosphorylation of Akt in monocyte-macrophages pretreated with CLI-095 (3 $\mu \mathrm{M})$ and infected with $S$. typhimurium (MOI = 10) $(\mathrm{E}-\mathrm{F})$ Fluorescence intensity of F-actin of monocyte-macrophages $(20 \times$ ELWD ADM). (G-H) Adhesive capacity of monocyte-macrophages (20× ELWD ADM). Tg: transgenic sheep; Wt: wild type sheep. All data are presented as the mean \pm SEM from three experiments, with $* \mathrm{P}<0.05$ and ** $\mathrm{P}<0.01$. 


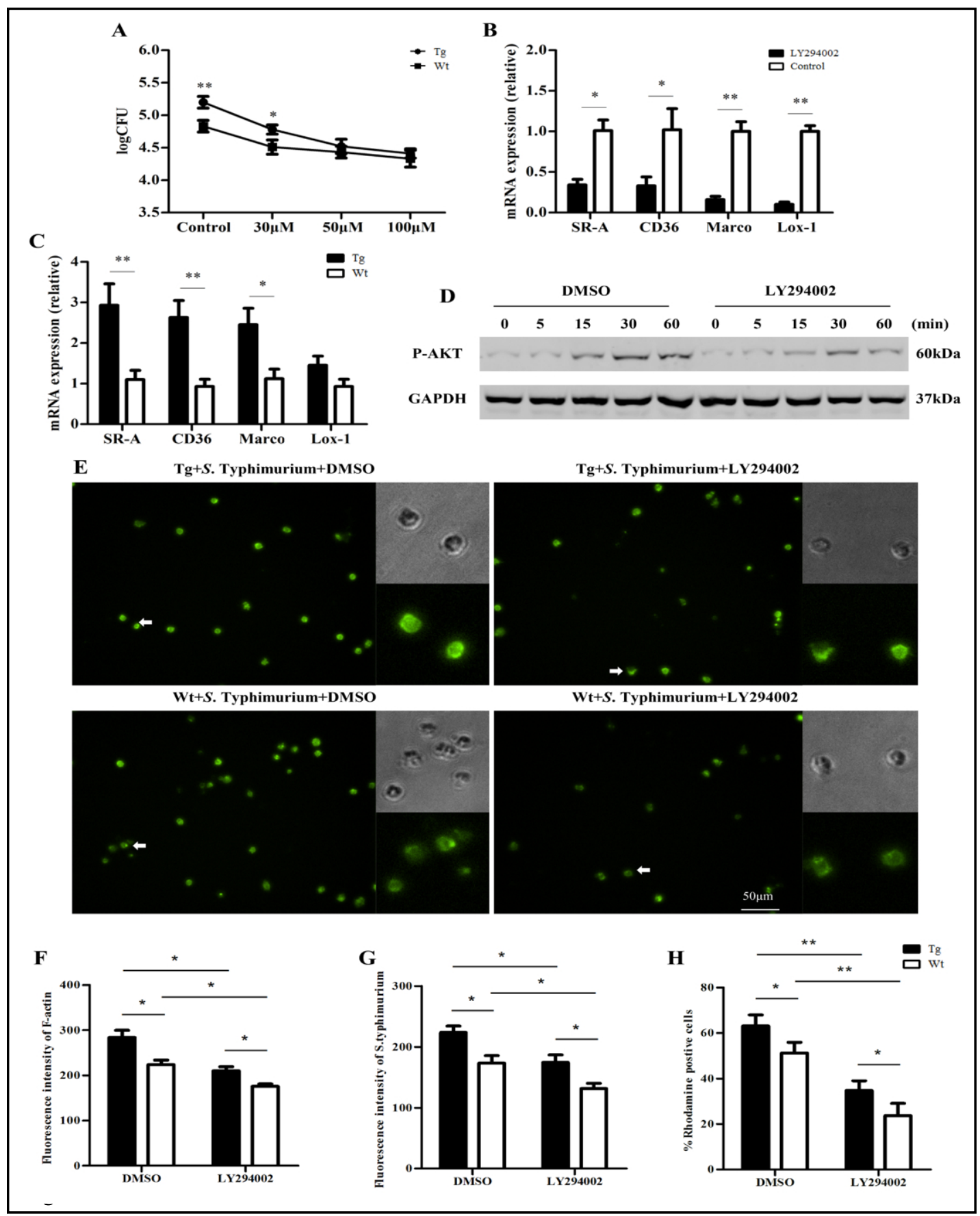

Fig. 6. Inhibition of PI3K signaling by LY294002 treatment reduced the phagocytosis of S. typhimurium in sheep monocyte-macrophages. (A) Monocyte-macrophages were pretreated with DMSO $(0.1 \%)$ or LY294002 $(0-100 \mu \mathrm{M})$ for $10 \mathrm{~min}$ and then bacterial internalization was detected after incubation with $S$. typhimurium for $30 \mathrm{~min}(\mathrm{MOI}=10)$. (B-C) qRT-PCR analysis of expression of SR-A, CD36, Marco, and Lox-1 from sheep monocyte-macrophages pretreated with LY294002 (30 $\mu \mathrm{M})$ and infected with S. typhimurium $(30 \mathrm{~min}, \mathrm{MOI}=10)$. (D) Show the phosphorylation of Akt in monocyte-macrophages pretreated with LY294002 $(30 \mu \mathrm{M})$ and infected with S. typhimurium (MOI = 10) (E-F) Fluorescence intensity of F-actin of monocyte-macrophages (20× ELWD ADM). (G-H) Adhesive capacity of monocyte-macrophages (20× ELWD ADM). Tg: transgenic sheep; Wt: wild type sheep. All data are presented as the mean \pm SEM from three experiments, with ${ }^{*} \mathrm{P}<0.05$ and ${ }^{* *} \mathrm{P}<0.01$. 


\section{Cellular Physiology Cell Physiol Biochem 2018;49:662-677

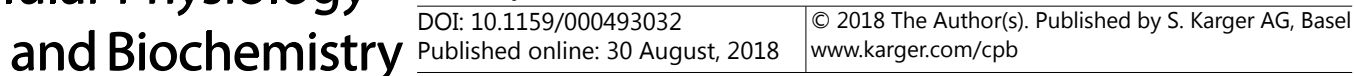 \\ Wang et al.: Overexpression of TLR4 Increase Phagocytosis in Transgenic Sheep}

\section{Discussion}

As pattern recognition receptors, TLRs recognize various molecules known as pathogenassociated molecular patterns (PAMPs) and activate the innate immune response [35]. Research efforts have generally focused on their function in the activation of inflammatory signaling pathways, which later activate NF- $\mathrm{BB}, \mathrm{AP}-1$, and other inflammatory cytokines [36]. Recently, many studies have suggested that TLR4 is involved in phagocytosis via its interaction with MAPK, Jak2, PI3K, and various receptors, which subsequently assist macrophages in recognizing and phagocytizing various bacteria [37-39]. We found that the TLR4-PI3K signaling pathway was involved in the internalization of $S$. typhimurium into sheep monocytes/macrophages by increasing the accumulation of F-actin and expression of the scavenger receptors, in addition to increasing the adhesive capacity of monocytes/ macrophages.

LPS is an important component of the cell wall of $S$. typhimurium. It is also a ligand of TLR4 that can quickly activate multiple signaling pathways within a few minutes [40], including those mediated by the NF- $\mathrm{BB}, \mathrm{MAPK}$, and PI3K signaling pathways $[12,37,41$, 42]. In particular, the NF- $\kappa B$ and MAPK signaling pathways have been shown to participate in inflammatory responses [36]. In contrast, the JAK-PI3K signaling pathway was shown to be involved in phagocytosis and apoptosis [38]. Our previous study reported that overexpression of TLR4 could trigger an intense inflammatory response and oxidative damage via increased secretion of IL- 6 , TNF- $\alpha$, and nitric oxide in sheep monocytes/ macrophages [32]. Here, we found a significant difference in the LPS-induced activation of Myd88, NF- $\kappa B$, and PI3K signaling between TLR4-overexpressing and wild-type sheep, suggesting that overexpression of TLR4 could more efficiently activate multiple signaling pathways in sheep monocytes/macrophages. This also suggests that LPS can induce a more intense innate immune response in TLR4-overexpressing sheep.

Similar to LPS-induced activation, several previous studies showed that Gram-negative bacteria infection quickly activates the Jak2, PI3K, AKT, and p38 signaling pathways within 30 min $[12,38]$. Our data indicated that $S$. typhimurium stimulation also caused higher expression of these factors in transgenic sheep. Moreover, monocytes/macrophages in TLR4overexpressing sheep phagocytized higher numbers of bacteria. The transgenic group also showed higher phagocytic ability when infected at a low dose (MOI $=10)$ and at an early time (5 min). Phagocytosis is a highly complicated process, such that a single model alone cannot explain particle internalization. In fact, multiple receptors are involved in the recognition of various particles and these receptors usually interact with each other [10]. Among them, scavenger receptors can recognize various ligands, including oxidized LDL (oxLDL), longchain fatty acids, and LPS, and are involved in a wide range of biological functions, including atherosclerosis, lipid metabolism, apoptotic cell clearance, and phagocytosis. CD14 is wellknown for its cooperation with TLR4 to help to bind LPS. In addition to TLR4, previous research has shown that scavenger receptors [43, 44] and CD14 [45] also participate in phagocytosis. Several previous studies have shown that TLR4, scavenger receptors [46], and CD14 [47] are capable of cross-talk and synergy. Our data show that overexpression of TLR4 could increase the expression of scavenger receptors but not those of CD14. One possible explanation is that CD14 and TLR4 are capable of cross-talk, but TLR4 overexpression does not affect the transcription of $C D 14$ in sheep monocytes/macrophages during S. typhimurium infection.

Despite the different receptors and mechanisms associated with phagocytosis, all forms of phagocytosis require actin polymerization at the location of ingestion [48]. Actin polymerization can be assessed by F-actin content $[12,49]$. Our study showed that actin polymerization increased with $S$. typhimurium stimulation. Furthermore, overexpression of TLR4 not only increased F-actin content, but also enhanced immunocyte adhesion, and these data were consistent with our findings for bacterial internalization. Moreover, TLR4 overexpression increased both the amount of bacteria adhered by individual monocytes/ macrophages and the number of monocytes/macrophages able to participate in bacterial 
adhesion. We also found that inhibition of TLR4 reduced S. typhimurium internalization, actin polymerization, scavenger receptor expression, and immunocyte adhesive capacity. Together, these data suggest that TLR4 regulates the phagocytosis of S. typhimurium in sheep monocytes/macrophages.

PI3K is important for downstream signaling of TLR4; however, it is controversial whether it participates in bacterial internalization [12, 13]. Schlam et al. showed that internalization of large, but not small $(<2 \mu \mathrm{m})$, particles requires PI3K [50]. Notably, a previous study [12] showed that inhibition of PI3K does not block internalization of E. coli. Another study showed that PI3K plays an important role in apoptotic cell phagocytosis [13]. However, in our experiments, phagocytosis of S. typhimurium was suppressed by LY294002, a PI3K-specific inhibitor. Thus, we considered the possibility that the different sizes of various particles could have resulted in these diverse outcomes. Although we found that PI3K participates in the phagocytosis of $S$. typhimurium, we wanted to determine how PI3K influences the phagocytosis of $S$. typhimurium. Several studies have shown that inhibition of PI3K reduces the expression of scavenger receptors [29] and suppresses the adhesion of monocytes/macrophages [30]. Our data show that inhibition of PI3K by LY294002 not only reduced the expression of scavenger receptors, but also suppressed the adhesion of the cells. Many phagocytosis receptors play dual roles, including both internalization and adhesion, and these two activities can activate each other $[19,20]$. Scavenger receptors often function by various mechanisms, including adhesion, phagocytosis, and signaling [51]. A previous study showed that CD36 is essential for LDL-induced macrophage spreading and actin polymerization [28]. Furthermore, SR-A-dependent macrophage adhesion can activate Rac and Cdc42 [52], which trigger actin polymerization. In addition, we found that actin polymerization of sheep immunocytes was suppressed by inhibition of PI3K and that this trend was consistent with our scavenger receptor expression results. Together, our findings suggest that PI3K enables phagocytosis of $S$. typhimurium by regulating the expression of scavenger receptors and actin polymerization as well as by changing the adhesive capacity of sheep monocytes/macrophages.

In our TLR4-overexpressing transgenic sheep, we found that, during phagocytosis of $S$. typhimurium, the expression levels of TLR4, PI3K, and scavenger receptors were all higher in the transgenic group than in the wild-type group. Furthermore, the F-actin content and adhesive capacity of sheep monocytes/ macrophages were also higher in the transgenic group. These findings may partly explain why TLR4-overexpressing transgenic sheep have a higher capacity for phagocytosis.

From a broader perspective, we provided evidence to show that $S$. typhimurium induces a complex intracellular signaling pathway for its internalization via TLR4. S. typhimurium infection probably triggers TLR4dependent activation of PI3K, with the subsequent activation of actin polymerization and scavenger receptors promoting the phagocytosis of bacteria in sheep (Fig. 7).

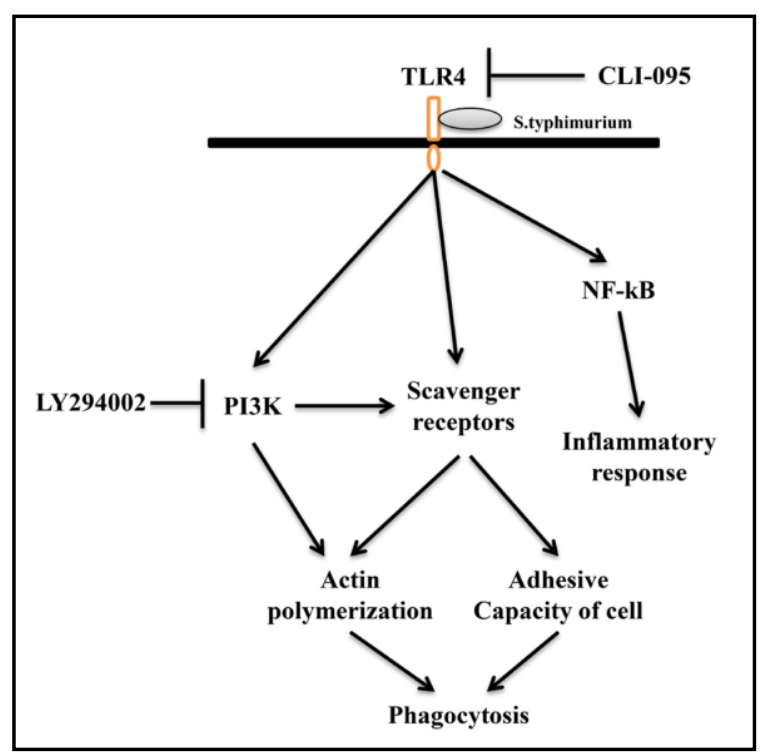

Fig. 7. Diagram illustrating the hypothesized signaling pathways involved in TLR4-PI3K activation during phagocytosis of $S$. typhimurium in sheep monocytemacrophages.

\section{KARGER}




\section{Cellular Physiology Cell Physiol Biochem 2018;49:662-677 \begin{tabular}{l|l|l} 
DOI: 10.1159/000493032 & O 2018 The Author(s). Published by S. Karger AG, Basel \\
wwww.karger.com/cpb
\end{tabular} \\ Wang et al.: Overexpression of TLR4 Increase Phagocytosis in Transgenic Sheep}

\section{Conclusion}

Under S. typhimurium stimulation, transgenic sheep can phagocytose more bacteria. This might enhance the immune response against bacterial infection. In addition, this study also provides valuable insight into the phagocytic mechanisms in sheep.

\section{Acknowledgements}

This work was supported by grants from the National Transgenic Creature Breeding Grand Project (2014ZX08008-005) and Tianjin Sci-Tech Plan Project (16ZXZYNC00050).

\section{Disclosure Statement}

No conflict of interests exists.

\section{References}

1 Davies RH, Evans SJ, Preece BE, Chappell S, Kidd S, Jones YE: Increase in Salmonella enterica subspecies diarizonae serovar 61:k:1, 5,(7) in sheep. Vet Rec 2001;149:555-557.

-2 Alvseike 0, Skjerve E: Prevalence of a Salmonella subspecies diarizonae in Norwegian sheep herds. Prev Vet Med 2002;52:277-285.

3 Zweifel C, Zychowska MA, Stephan R: Prevalence and characteristics of Shiga toxin-producing Escherichia coli, Salmonella spp. and Campylobacter spp. isolated from slaughtered sheep in Switzerland. Int J Food Microbiol 2004;92:45-53.

4 Tsolis RM, Kingsley RA, Townsend SM, Ficht TA, Adams LG, Baumler AJ: Of mice, calves, and men. Comparison of the mouse typhoid model with other Salmonella infections. Adv Exp Med Biol 1999;473:261-274.

-5 Suzuki H, Kurihara Y, Takeya M, Kamada N, Kataoka M, Jishage K, Ueda O, Sakaguchi H, Higashi T, Suzuki T, Takashima Y, Kawabe Y, Cynshi O, Wada Y, Honda M, Kurihara H, Aburatani H, Doi T, Matsumoto A, Azuma S et al.: A role for macrophage scavenger receptors in atherosclerosis and susceptibility to infection. Nature 1997;386:292-296.

6 Haraga A, Ohlson MB, Miller SI: Salmonellae interplay with host cells. Nat Rev Microbiol 2008;6:53-66.

7 Medzhitov R: Toll-like receptors and innate immunity. Nat Rev Immunol 2001;1:135-145.

8 Takeda K, Akira S: Toll receptors and pathogen resistance. Cell Microbiol 2003;5:143-153.

-9 Zhang DCPCQ: Requirements for Both Rac1 and Cdc42 in Membrane Ruffling and Phagocytosis in Leukocytes. J.Exp. Med 1997;186:1487-1494.

10 M.Underhill AD: MECHANISMS OF PHAGOCYTOSIS IN MACROPHAGES. Annu. Rev. Immunol 1999;17:593623.

11 Deng S, Yu K, Jiang W, Li Y, Wang S, Deng Z, Yao Y, Zhang B, Liu G, Liu Y, Lian Z: Over-expression of Toll-like receptor 2 up-regulates heme oxygenase-1 expression and decreases oxidative injury in dairy goats. J Anim Sci Biotechnol 2017;8:3.

12 Kong L, Ge BX: MyD88-independent activation of a novel actin-Cdc42/Rac pathway is required for Toll-like receptor-stimulated phagocytosis. Cell Res 2008;18:745-755.

13 Leverrier Y, Okkenhaug K, Sawyer C, Bilancio A, Vanhaesebroeck B, Ridley AJ: Class I phosphoinositide 3-kinase p110beta is required for apoptotic cell and Fcgamma receptor-mediated phagocytosis by macrophages. J Biol Chem 2003;278:38437-38442.

14 Heit B, Liu L, Colarusso P, Puri KD, Kubes P: PI3K accelerates, but is not required for, neutrophil chemotaxis to fMLP. J Cell Sci 2008;121:205-214.

15 Kortholt A, Bolourani P, Rehmann H, Keizer-Gunnink I, Weeks G, Wittinghofer A, Van Haastert PJ: A Rap/phosphatidylinositol 3-kinase pathway controls pseudopod formation [corrected]. Mol Biol Cell 2010;21:936-945. 


\section{Cellular Physiology Cell Physiol Biochem 2018;49:662-677 \begin{tabular}{ll|l} 
DOI: 10.1159/000493032 & $\begin{array}{l}\text { O 2018 The Author(s). Published by S. Karger AG, Basel } \\
\text { www.karger.com/cpb }\end{array}$
\end{tabular} \\ Wang et al.: Overexpression of TLR4 Increase Phagocytosis in Transgenic Sheep}

16 Araki N, Hatae T, Furukawa A, Swanson JA: Phosphoinositide-3-kinase-independent contractile activities associated with Fcgamma-receptor-mediated phagocytosis and macropinocytosis in macrophages. J Cell Sci 2003;116:247-257.

17 Allen LA, Allgood JA, Han X, Wittine LM: Phosphoinositide3-kinase regulates actin polymerization during delayed phagocytosis of Helicobacter pylori. J Leukoc Biol 2005;78:220-230.

18 Freeman SA, Grinstein S: Phagocytosis: receptors, signal integration, and the cytoskeleton. Immunol Rev 2014;262:193-215.

19 Pommier CG, Inada S, Fries LF, Takahashi T, Frank MM, Brown EJ: Plasma fibronectin enhances phagocytosis of opsonized particles by human peripheral blood monocytes. J Exp Med 1983;157:18441854.

-20 Wright SD, Craigmyle LS, Silverstein SC: Fibronectin and serum amyloid P component stimulate C3b- and C3bi-mediated phagocytosis in cultured human monocytes. J Exp Med 1983;158:1338-1343.

-21 Sastry K, Ezekowitz RA: Collectins: pattern recognition molecules involved in first line host defense. Curr Opin Immunol 1993;5:59-66.

22 Krieger M, Herz J: Structures and functions of multiligand lipoprotein receptors: macrophage scavenger receptors and LDL receptor-related protein (LRP). Annu Rev Biochem 1994;63:601-637.

23 Stahl PD ER: The mannose receptor is a pattern recognition receptor involved in host defense. Curr Opin Immunol 1998;10:50-55.

-24 Hsu HY, Hajjar DP, Khan KM, Falcone DJ: Ligand binding to macrophage scavenger receptor-A induces urokinase-type plasminogen activator expression by a protein kinase-dependent signaling pathway. J Biol Chem 1998;273:1240-1246.

25 Hsu HY, Chiu SL, Wen MH, Chen KY, Hua KF: Ligands of macrophage scavenger receptor induce cytokine expression via differential modulation of protein kinase signaling pathways. J Biol Chem 2001;276:2871928730.

-26 van Velzen AG, Suzuki H, Kodama T, van Berkel TJ: The role of scavenger receptor class A in the adhesion of cells is dependent on cell type and cellular activation state. Exp Cell Res 1999;250:264-271.

27 Moore KJ, El Khoury J, Medeiros LA, Terada K, Geula C, Luster AD, Freeman MW: A CD36-initiated signaling cascade mediates inflammatory effects of beta-amyloid. J Biol Chem 2002;277:47373-47379.

28 Park YM, Febbraio M, Silverstein RL: CD36 modulates migration of mouse and human macrophages in response to oxidized LDL and may contribute to macrophage trapping in the arterial intima. J Clin Invest 2009;119:136-145.

-29 Michael DR, Davies TS, Laubertova L, Gallagher H, Ramji DP: The phosphoinositide 3-kinase signaling pathway is involved in the control of modified low-density lipoprotein uptake by human macrophages. Lipids 2015;50:253-260.

-30 Cholewa J, Nikolic D, Post SR: Regulation of class A scavenger receptor-mediated cell adhesion and surface localization by PI3K: identification of a regulatory cytoplasmic motif. J Leukoc Biol 2010;87:443-449.

-31 Bihl F, Salez L, Beaubier M, Torres D, Lariviere L, Laroche L, Benedetto A, Martel D, Lapointe JM, Ryffel B, Malo D: Overexpression of Toll-like receptor 4 amplifies the host response to lipopolysaccharide and provides a survival advantage in transgenic mice. J Immunol 2003;170:6141-6150.

-32 Deng S, Wu Q Yu K, Zhang Y, Yao Y, Li W, Deng Z, Liu G, Li W, Lian Z: Changes in the relative inflammatory responses in sheep cells overexpressing of toll-like receptor 4 when stimulated with LPS. PLoS One 2012;7:e47118.

33 Deng S, Yu K, Wu Q Li Y, Zhang X, Zhang B, Liu G, Liu Y, Lian Z: Toll-Like Receptor 4 Reduces Oxidative Injury via Glutathione Activity in Sheep. Oxid Med Cell Longev 2016;2016:9151290.

-34 Deng S, Yu K, Zhang B, Yao Y, Wang Z, Zhang J, Zhang X, Liu G, Li N, Liu Y, Lian Z: Toll-Like Receptor 4 Promotes NO Synthesis by Upregulating GCHI Expression under Oxidative Stress Conditions in Sheep Monocytes/Macrophages. Oxid Med Cell Longev 2015;2015:359315.

-35 Kawai T, Akira S: The role of pattern-recognition receptors in innate immunity: update on Toll-like receptors. Nat Immunol 2010;11:373-384.

36 Kawai T, Akira S: TLR signaling. Cell Death Differ 2006;13:816-825.

-37 Doyle SE, O’Connell RM, Miranda GA, Vaidya SA, Chow EK, Liu PT, Suzuki S, Suzuki N, Modlin RL, Yeh WC, Lane TF, Cheng G: Toll-like receptors induce a phagocytic gene program through p38. J Exp Med 2004;199:81-90. 


\section{Cellular Physiology Cell Physiol Biochem 2018;49:662-677

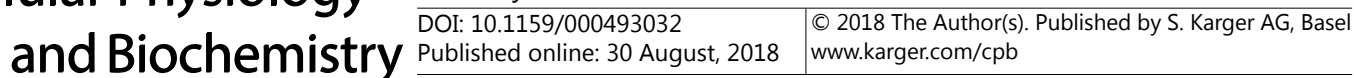 \\ Wang et al.: Overexpression of TLR4 Increase Phagocytosis in Transgenic Sheep}

38 Kim JJLDH: Toll-Like Receptor 4-Linked Janus Kinase 2 Signaling Contributes to Internalization of Brucella abortus by Macrophages. Infection and Immunity 2013;81:2448-2458.

39 Wong CE, Sad S, Coombes BK: Salmonella enterica serovar typhimurium exploits Toll-like receptor signaling during the host-pathogen interaction. Infect Immun 2009;77:4750-4760.

40 Deng M, Scott MJ, Loughran P, Gibson G, Sodhi C, Watkins S, Hackam D, Billiar TR: Lipopolysaccharide clearance, bacterial clearance, and systemic inflammatory responses are regulated by cell type-specific functions of TLR4 during sepsis. J Immunol 2013;190:5152-5160.

41 CAR BSPCMaBD: Inhibition of kinases impairs neutrophil activation and killing of Staphylococcus aureus. Biochem. J. 1998;331:489-495.

42 Tapper GPDJRBH: Importance of MEK in Neutrophil Microbicidal Responsiveness. J Immunol 1998;160:434-443.

43 Savill J, Hogg N, Ren Y, Haslett C: Thrombospondin cooperates with CD36 and the vitronectin receptor in macrophage recognition of neutrophils undergoing apoptosis. J Clin Invest 1992;90:1513-1522.

44 Kurihara NPHSY: Role for the class A macrophage scavenger receptor in the phagocytosis of apoptotic thymocytes in vitro. PNAS 1996;93:12456-12460.

45 Raykundalia ADODMC: Human CD14 mediates recognition and phagocytosis of apoptotic cells. Nature 1998;392:505-509.

46 Cao D, Luo J, Chen D, Xu H, Shi H, Jing X, Zang W: CD36 regulates lipopolysaccharide-induced signaling pathways and mediates the internalization of Escherichia coli in cooperation with TLR4 in goat mammary gland epithelial cells. Sci Rep 2016;6:23132.

-47 Ben Haij N, Planes R, Leghmari K, Serrero M, Delobel P, Izopet J, BenMohamed L, Bahraoui E: HIV-1 Tat Protein Induces Production of Proinflammatory Cytokines by Human Dendritic Cells and Monocytes/ Macrophages through Engagement of TLR4-MD2-CD14 Complex and Activation of NF-kappaB Pathway. PLoS One 2015;10:e0129425.

48 Mao Y, Finnemann SC: Regulation of phagocytosis by Rho GTPases. Small GTPases 2015;6:89-99.

$\$ 49$ Karavitis J, Murdoch EL, Deburghgraeve C, Ramirez L, Kovacs EJ: Ethanol suppresses phagosomal adhesion maturation, Rac activation, and subsequent actin polymerization during FcgammaR-mediated phagocytosis. Cell Immunol 2012;274:61-71.

50 Schlam D, Bagshaw RD, Freeman SA, Collins RF, Pawson T, Fairn GD, Grinstein S: Phosphoinositide 3-kinase enables phagocytosis of large particles by terminating actin assembly through Rac/Cdc42 GTPaseactivating proteins. Nat Commun 2015;6:8623.

51 PrabhuDas MR, Baldwin CL, Bollyky PL, Bowdish DME, Drickamer K, Febbraio M, Herz J, Kobzik L, Krieger M, Loike J, McVicker B, Means TK, Moestrup SK, Post SR, Sawamura T, Silverstein S, Speth RC, Telfer JC, Thiele GM, Wang XY, Wright SD, El Khoury J: A Consensus Definitive Classification of Scavenger Receptors and Their Roles in Health and Disease. J Immunol 2017;198:3775-3789.

52 Nikolic DM, Gong MC, Turk J, Post SR: Class A scavenger receptor-mediated macrophage adhesion requires coupling of calcium-independent phospholipase A(2) and 12/15-lipoxygenase to Rac and Cdc42 activation. J Biol Chem 2007;282:33405-33411. 